\title{
1. COMPARISON OF SEISMIC REFLECTION DATA TO A SYNTHETIC SEISMOGRAM IN A VOLCANIC APRON AT SITE 953 ${ }^{1}$
}

\author{
Thomas Funck ${ }^{2}$ and Holger Lykke-Andersen ${ }^{3}$
}

\begin{abstract}
The volcanic apron of Gran Canaria at Site 953 is characterized by numerous, closely spaced reflectors, allowing a highresolution stratigraphic correlation. The calibration of the presite survey seismic data (during the Meteor Cruise 24) with regard to the lithology and stratigraphy found at the drill site was achieved by computing a synthetic seismogram serving as the link between seismic and borehole data. Because logging data were available for only $53 \%$ of the hole, velocity and density measurements taken from the recovered cores were used in the missing intervals to obtain a complete synthetic seismogram. Most reflectors in the upper $\sim 900 \mathrm{~m}$ of the sequence (lithologic Units I-V) turned out to be thin volcaniclastic layers intercalated to the nonvolcanic background sediments. Their thicknesses are generally $<2 \mathrm{~m}$, and the reflections from their tops and bases overlap, forming a single reflection. The limit of the seismic detection of such interbeds is on the order of several decimeters and thus requires special care for the processing of the velocity and density data to avoid destruction of the signal from these thin layers.
\end{abstract}

\section{INTRODUCTION}

The volcanic apron of Gran Canaria consists of volcaniclastic deposits with generally high $P$-wave velocities and densities intercalated to the hemipelagic background sediments with lower velocities and densities (Schmincke, Weaver, Firth, et al., 1995). Although the volcaniclastic layers are generally $<1 \mathrm{~m}$ thick, they are conspicuous in the seismic record by their continuity outside the chaotic or discontinuous slope facies proximal to the island. Because prominent reflectors can be used as marker horizons for the mapping of the apron, it is worthwhile to calculate synthetic seismograms for correlating the seismic data with the lithology and stratigraphy at the drill sites.

Site 953 (Fig. 1) is the deepest site around Gran Canaria (maximum penetration 1159 meters below seafloor [mbsf]), reflecting the entire volcanic and erosional evolution of the island. It thus represents a key site for the calibration of seismic data. The computed synthetic seismogram is compared with the high-resolution seismic reflection Profile 134 (Fig. 1) where Site 953 is located. This profile was collected during the presite survey of the vessel Meteor Cruise 24 (Schmincke and Rihm, 1994).

The objective of this study was to calculate a complete synthetic seismogram to benefit as much as possible from the drilling results for the seismic interpretation. Special care had to be taken in processing the density and velocity data to preserve the signal of the thin volcaniclastic interbeds.

\section{DATA PREPARATION}

The standard method of obtaining synthetic seismograms is to use impedance $\operatorname{logs}$ from downhole measurements. Impedance is the product of $P$-wave velocity and bulk density. However, because Site

${ }^{1}$ Weaver, P.P.E., Schmincke, H.-U., Firth, J.V., and Duffield, W. (Eds.), 1998. Proc. ODP, Sci. Results, 157: College Station, TX (Ocean Drilling Program).

${ }^{2}$ Graduiertenkolleg, GEOMAR, Wischhofstr. 1-3, 24148 Kiel, Federal Republic of Germany. (Present address: Department of Oceanography, Dalhousie University, Halifax, Nova Scotia, B3H 4J1, Canada. tfunck@is.dal.ca).

${ }^{3}$ Department of Earth Sciences, University of Århus, Finlandsgade 8, 8200 Århus N, Denmark.
953 was not logged intensely (only $53 \%$ of the hole was logged), the logging data set alone was not sufficient to compute a synthetic seismogram for the entire hole. Gaps in the logging data therefore were filled with laboratory measurements carried out on the recovered sediments aboard ship.

At Site 953, a huge amount of overlapping velocity and density measurements was available. Velocity data were provided by the $P$ wave logger of the multisensor track (MST; depth interval 0-192 mbsf), digital sound velocimeter (DSV; 0-76 mbsf), Hamilton frame (187-1159 mbsf), and sonic log (372-963 mbsf). Density data were available from the gamma-ray attenuation porosity evaluator (GRAPE) sensor of the MST (0-1159 mbsf), the index properties (0$1159 \mathrm{mbsf})$, and the density $\log (372-987 \mathrm{mbsf})$. These data had to be processed and merged in a trial and error process to find the best correlation between seismic Line 134 and the computed synthetic seismogram.

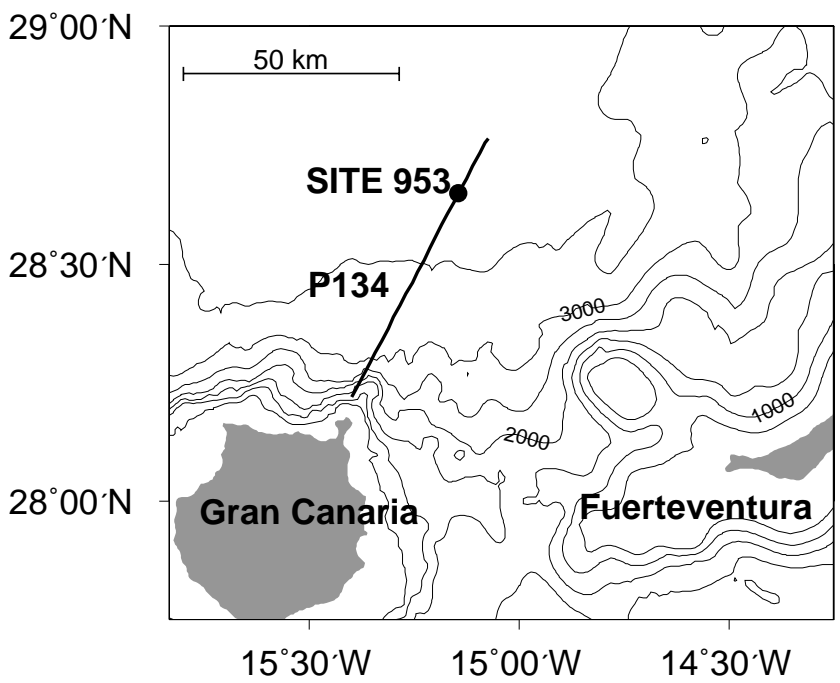

Figure 1. Generalized bathymetry chart of the volcanic apron north of Gran Canaria (contours at 500-m intervals), showing the location of Site 953 and the crossing reflection seismic Line P134 of the Meteor Cruise 24. 
In the end, the MST data (0-192 mbsf) were used for the first part of the final velocity function (Fig. 2), because the data density of the overlapping DSV data was only $\sim 1$ per $5 \mathrm{~m}$. The erroneous values at the ends of each measured core section ( $1.5 \mathrm{~m}$ length) were deleted. Furthermore, a median filter (filter length $0.25 \mathrm{~m}$ ) had to be applied because the broad scatter in the data introduced artificial reflections. The second part of the velocity function consists of Hamilton frame data (192-372 mbsf) as no other data were available. The third part was provided by the sonic $\log (372-963 \mathrm{mbsf})$. Because the main part of reflections is produced by only thin (meter-sized or even less) interbeds of volcaniclastic material, the best results were achieved using raw data, although some spikes were probably erroneous; in fact, filtering the logging data seemed to overly flatten the characteristics (amplitudes became too low). The last part of the velocity function was made again using the Hamilton frame (963-1157 mbsf); however, a velocity correction had to be applied because the synthetic seismogram did not fit well with the measured data in the lowermost part. A systematic offset was detected below $\sim 720$ mbsf, where the Hamilton frame velocities were systematically higher than the logging velocities. The reason for this deviation is unclear; possible explanations include

1. Systematic error in the Hamilton frame measuring instrument (improbable);

2. Selective coring, (i.e., softer sediments with a lower velocity tend to be washed out of the core);

3. Selective measuring, that is, the measured points are not representative for the cored sediments; and

4. Anisotropy, because the velocity measured using the Hamilton frame was made perpendicular to the core axis (i.e., in the bedding plane and not along the core axis).
Nevertheless, the average velocity for the interval 720-963 mbsf was $306 \mathrm{~m} / \mathrm{s}$ higher for the Hamilton frame than for the sonic log so that $306 \mathrm{~m} / \mathrm{s}$ was applied as the velocity correction below $963 \mathrm{mbsf}$.

The final density function contains only index properties measurements. The GRAPE density was eliminated because the necessary filtering of the values for the upper interval (0-192 mbsf), in combination with the smooth-filtered MST velocities, did not produce the necessary impedance variations to fit the observed reflections. In the lower interval down to 1159 mbsf, the GRAPE densities are erroneous because the applied rotary drilling technique resulted in core disturbances and variable core diameters. The decision whether to use index properties or the density log was made on the basis of a comparison of the correlation with the seismic data. The index properties proved to be slightly better.

The average density and velocity increase with depth because of the increasing consolidation and compaction of the hemipelagic background sediments. Volcaniclastic interbeds show generally pronounced deviations from this average, with a maximum of $3.1 \mathrm{~g} / \mathrm{cm}^{3}$ in density and $5.3 \mathrm{~km} / \mathrm{s}$ in velocity. Figure 2 shows that peaks in velocity do not always correlate with peaks in density, because such intervals are not sampled by both data sets, especially where core recovery is low.

\section{SYNTHETIC SEISMOGRAM}

The depths of velocity and density function derived from merging the different data sources were converted to time using the time-depth relation calculated from the velocity. The data were then sampled at $1 \mathrm{~m} / \mathrm{s}$ intervals, and the reflectivity was derived from two successive samples (Fig. 2). The reflectivity was then convolved with the source
Figure 2. Computation of the synthetic seismogram at Site 953. The bulk density is derived from the index properties. The $P$-wave velocity is composed of multisensor track, Hamilton frame, and sonic log data. The vertical axis shows the TWT below seafloor. The synthetic seismogram results from the reflectivity convolved with the source wavelet used during the Meteor Cruise 24 presite survey. The AGC is applied to the synthetic traces.

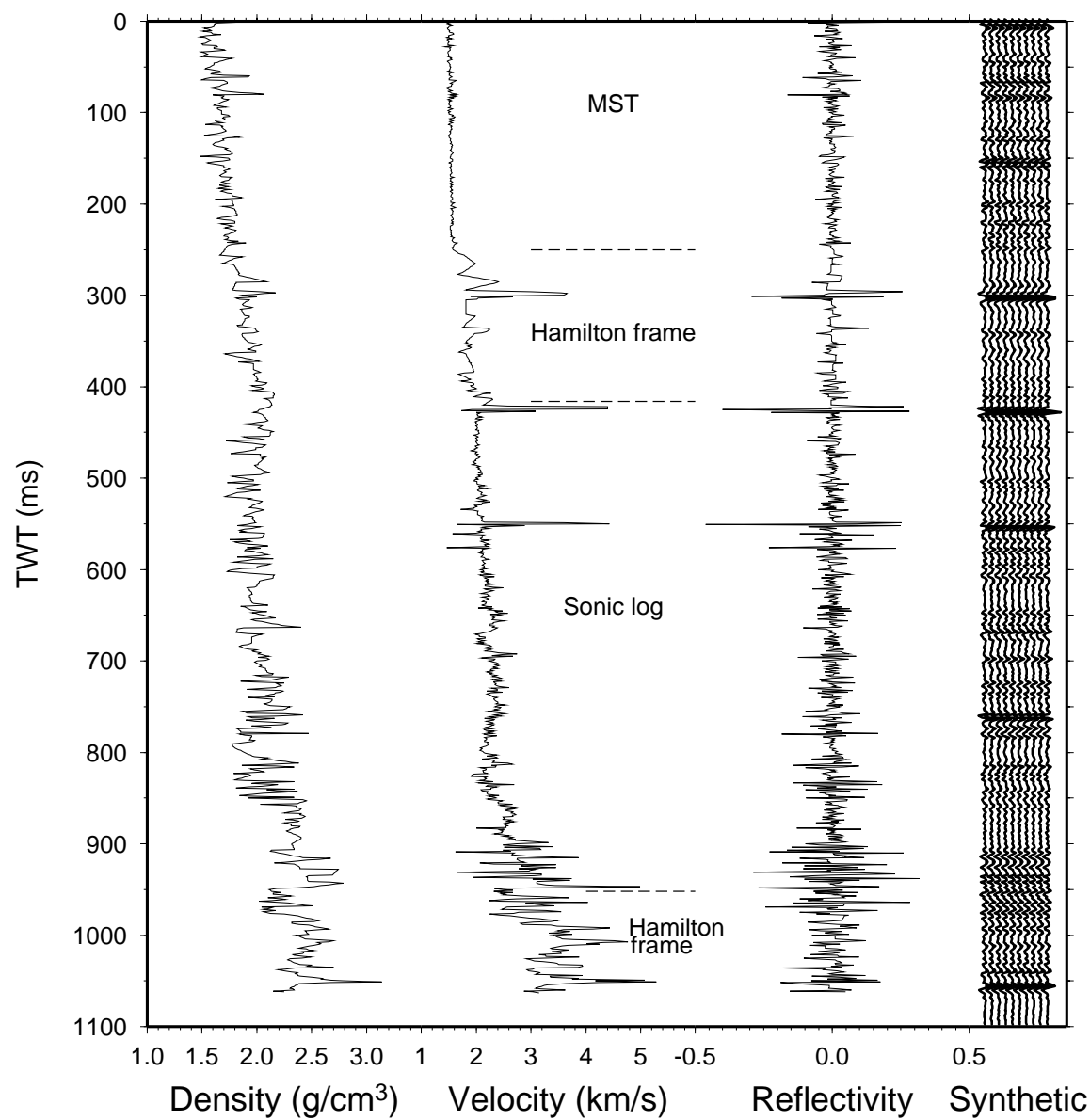


wavelet used during the reflection seismic survey. The wavelet was computed from stacking 100 direct arrivals using the same sleevegun cluster $(4 \times 0.651)$ as during the Meteor Cruise 24 (Larsen, Saunders, Clift, et al., 1994). The computed synthetic seismogram does not comprise internal multiples, even though some peg-leg multiples between the volcaniclastic horizons are likely. However, because gaps in the velocity and density data sets occurred preferentially in the coarse-grained volcaniclastic intervals, a number of erroneous multiple reflections would be introduced to the synthetic seismogram.

To match the real and synthetic data as close as possible, the same time-variant band-pass-filter and automatic gain control (AGC), as used in the processing of the real data, was applied to the synthetic data (Fig. 3). Furthermore, random noise was added to the synthetic data. Differences between the synthetic seismogram and the seismic profile occur where the data density was not adequate to detect thin interbeds. Discrepancies shallower than $5.0 \mathrm{~s}$ two-way traveltime (TWT) are, for example, caused by an insufficient sampling rate for the index properties measurements, caused by the rapid flow of cores in the laboratory. Further downcore (down to $\sim 5.15 \mathrm{~s}$ and below 5.65 s TWT), many intervals had low core recovery, probably masking some reflectors. Nevertheless, the synthetic seismogram fits the seismic data surprisingly well considering that only half of the site was logged.

\section{CORRELATION OF SEISMIC DATA WITH LITHOLOGY}

By means of the synthetic seismogram computed for Site 953, a number of reflectors could be assigned to specific lithologies, mainly volcaniclastic interbeds in the hemipelagic background sediments. Reflectors identified in the seismic data and in the synthetic seismogram are listed in Table 1, and, when possible, the reflecting lithology is given. Several of these lithologies are labeled with question marks, indicating that the reflection could not be determined unequivocally. For example, this might be the case where amplitudes did not fit very well or where lithologies in the vicinity were not sampled but could have caused the reflection. Where only one lithology is given, the reflection is caused by the interference of the top and bottom reflection of a thin interbed surrounded by sediments with a different impedance. These layers are generally thinner than $2 \mathrm{~m}$, often $<1 \mathrm{~m}$.

The reflectors are numbered from the seafloor (No. 0) downcore (Fig. 4). The age of the reflectors is taken from biostratigraphic and paleomagnetic data (Brunner et al., Chap. 9, this volume). Some reflectors, which are suitable for regional mapping because of their continuity and amplitude, are labeled with letters, corresponding to volcanic phases on Gran Canaria (Schmincke, 1976, 1982, 1994; Hoernle and Schmincke, 1993a, 1993b) and the neighboring island Tenerife in the west (Ancochea et al., 1990). The sediments causing the reflectors $\mathrm{M}$ and $\mathrm{F}$ were deposited during the Mogan and Fataga phase of the Miocene volcanism on Gran Canaria. Reflector H represents the transition to the volcanic hiatus on Gran Canaria, reflector $\mathrm{T}$ is generated by sediments deposited during the shield stage of Tenerife, reflector RN corresponds to the Pliocene Roque Nublo volcanism on Gran Canaria, and the sediments causing reflector Q were deposited in the Quaternary with volcanic activity both on Gran Canaria and Tenerife. This reflector nomenclature was introduced by Funck (1996). Comparison between reflectors found at the Deep Sea Drilling Project (DSDP) Site 397 (Wissmann, 1979; von Rad, Ryan, et al., 1979) or Ocean Drilling Program Sites 955 and 956 (Schmincke, Weaver, Firth, et al., 1995) south of Gran Canaria is hampered because of the influence of the continental slope, whereas the northern basin is more or less shielded from continental input by the East $\mathrm{Ca}$ nary Ridge. Furthermore, no direct seismic correlation from south to north is possible across the channel between Gran Canaria and Fuerteventura/Tenerife, because the reflectors onlap the volcanic basement and/or reflection patterns become chaotic in the proximity of the islands. This explains why reflector names introduced for the southern basin at DSDP Site 397 are not suitable in the north. However, the prominent reflector bands R7 and R3 at DSDP Site 397 (von Rad, Ryan, et al., 1979) correspond to the reflector bands around M and RN, respectively, based on their depositional age and seismic facies (Funck et al., 1996).

\section{DISCUSSION AND CONCLUSIONS}

The high-resolution seismic data of the Meteor Cruise 24 revealed a large number of reflectors from which 55 (Table 1) could be identified by means of the synthetic seismogram at Site 953 . The depositional setting of the volcanic apron of Gran Canaria with its thin volcaniclastic layers intercalated to the nonvolcanic background sediments put great demands on the preparation of the velocity and density data. For example, filtering can remove unrealistic spikes but also can eliminate the signal of thin layers. Another difficulty that occurred at Site 953 was the incomplete logging data set resulting in the use of discrete measurements carried out on the cores. Apart from the fact that these data were only available for the cored intervals, two problems occurred in the case of the investigated volcanic apron:

1. The use of the closely sampled $(0.5-3.0 \mathrm{~cm}) \mathrm{MST}$ data with its broad scatter resulted in artificial reflections, whereas filtering destroyed almost all real signals from thin layers.

2. The typical sampling rate of one per section $(1.5 \mathrm{~m})$ for the index properties, the Hamilton frame, and DSV measurements often proved to be insufficient to record all reflectors.

Nevertheless, the careful composition of the velocity and density function allowed identification of most of the reflectors. The reflectors in lithologic Units I-V (Fig. 4) represent thin layers, generally <2 $\mathrm{m}$ thick. This raises the question of the vertical resolution of the seismic data. Badley (1985) states that an interbedded layer has to be thicker than half the seismic wavelength to enable resolution of its top and base. Thinner layers appear as one single reflector with a maximum amplitude at one-quarter wavelength - the tuning thickness. For thicknesses below one-quarter wavelength, the reflection remains the same shape, but decreases in amplitude. Once the thickness is about one-thirtieth wavelength or less, there is no detectable response. This explains why thin volcaniclastic beds can be detected as single reflectors. Applying this knowledge to the data reported here, the signal contains frequencies of up to $230 \mathrm{~Hz}$, and the velocity in the volcaniclastic layers is typically between 1700 and $2000 \mathrm{~m} / \mathrm{s}$ in the upper $100 \mathrm{~m}$. One-thirtieth of a wavelength thus corresponds to only $25-30 \mathrm{~cm}$, which is the minimum thickness for seismic detection of such layers. Frequencies around the maximum energy of the source wavelet $(\sim 80-100 \mathrm{~Hz})$ correspond to a detection limit in the order of $50-80 \mathrm{~cm}$. Weak and discontinuous reflectors seem to represent thin layers with a thickness on the order of one-thirtieth of the wavelength. This is the case for the thin sand layers that are recognizable in the upper $50 \mathrm{~m}$ of the seismic record in Fig. 3. Their thicknesses at Site 953 are $~ 80 \mathrm{~cm}$ (Schmincke, Weaver, Firth, et al., 1995).

Another point to discuss here briefly is the boundaries of the lithologic units and their seismic expression. Most of the lithologic boundaries are not characterized by reflections, at least not by reflections with a high continuity and amplitude (Fig. 4). The reason for this is simply the fact that the main criterion to subdivide the sequence into lithologic units was the variation of the flux of coarse material to Site 953 (Schmincke, Weaver, Firth, et al., 1995). This flux was averaged for larger intervals (core length), and therefore the lithologic boundaries typically do not correspond to a volcaniclastic interbed and its associated reflection. The boundary between lithologic Units VI and V, separating the massive basaltic pedestal of Gran Canaria from the overlying sediments, is characterized by a high amplitude reflection and represents an exception to the other- 


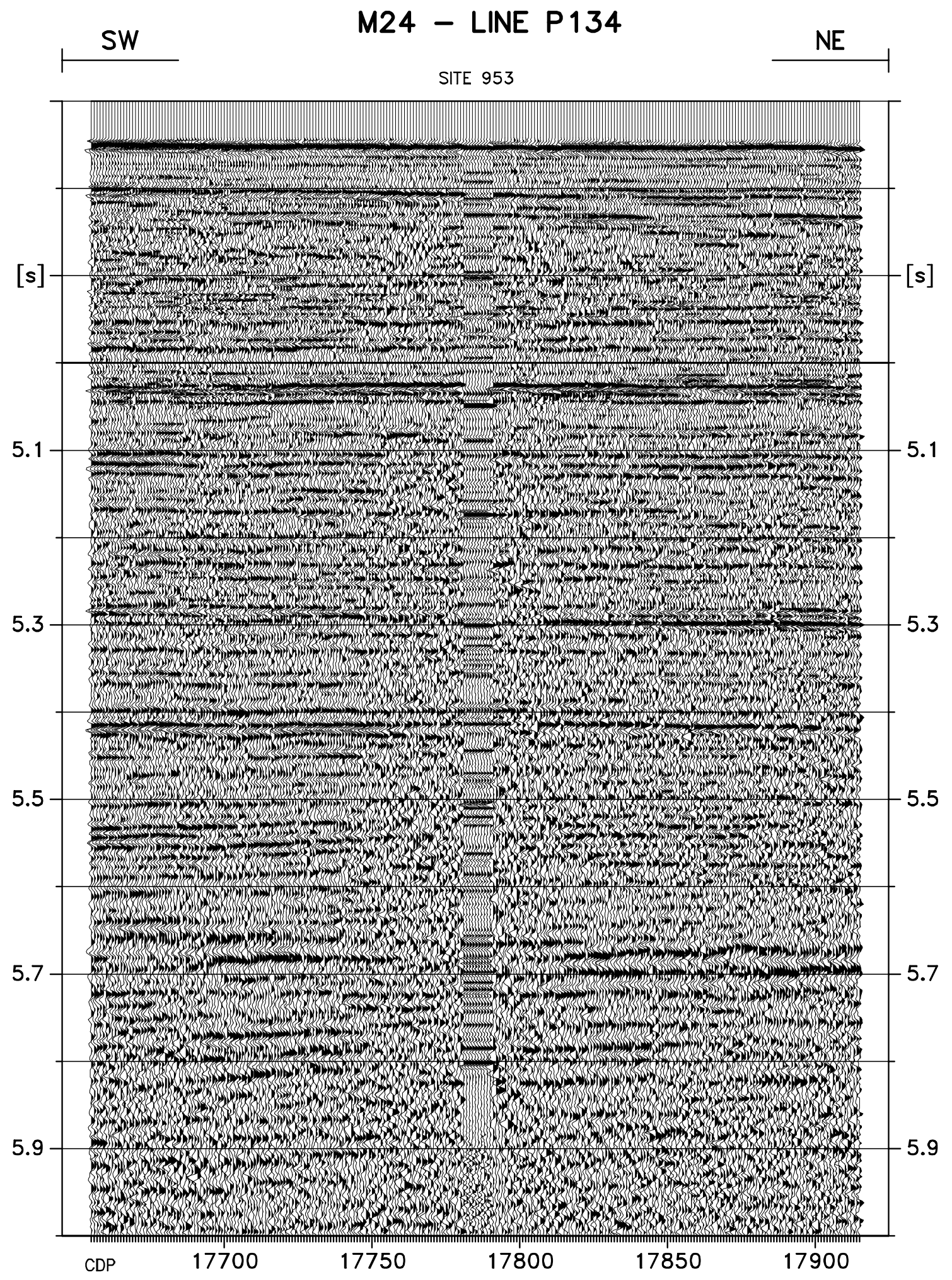

Figure 3. Part of seismic Line P134 is plotted together with the synthetic seismogram at Site 953. The seismic data are stacked, scaled with an AGC (50-200 $\mathrm{ms}$ ), and band-pass filtered (30-230 Hz at seafloor, $30-160 \mathrm{~Hz}$ at $6 \mathrm{~s}$ TWT). Random noise was added to the 10 synthetic seismic traces. One common depth point (CDP) corresponds to a horizontal distance of $3.125 \mathrm{~m}$, and the TWT is given in seconds below sea level. 
Table 1. Correlated reflectors at Site 953.

\begin{tabular}{|c|c|c|c|c|}
\hline Reflector & Depth (mbsf) & TWT (ms) & Age (Ma) & Reflection causing lithologies (and comments) \\
\hline 0 & 0.00 & 4745 & 0.00 & Seafloor \\
\hline 1 & 11.45 & 4760 & 0.36 & Clayey medium to coarse-grained silty pumice sand \\
\hline 2 & 20.60 & 4772 & 0.48 & Silty fine medium-grained foraminifer pumice sand \\
\hline 3 & 23.90 & 4777 & 0.53 & Calcareous sand \\
\hline 4 & 30.17 & 4785 & 0.61 & Basaltic sand \\
\hline 5 & 45.85 & 4805 & 0.82 & Silty crystal lithic sand (amplitude difference due to low recovery) \\
\hline 6 & 55.49 & 4818 & 0.95 & Clayey nannofossil ooze (weak reflector) \\
\hline 7 & 60.77 & 4826 & 1.03 & Crystal lithic sand \\
\hline 8 & 72.61 & 4840 & 1.19 & Calcareous sand with volcanic lithics \\
\hline 9 & 96.40 & 4871 & 1.51 & Foraminifer lithic sand \\
\hline 10 & 130.73 & 4916 & 1.97 & Massive lithic to calcareous sand \\
\hline 11 & 149.74 & 4940 & 2.23 & Massive foraminifer sand with lithics (weak reflector, low continuity) \\
\hline 12 & 170.53 & 4967 & 2.62 & Foraminifer silt with lithics and crystals \\
\hline 13 & 176.00 & 4974 & 2.70 & Clayey nannofossil ooze? \\
\hline 14 & 206.23 & 5010 & 3.12 & Foraminifer sandstone \\
\hline 15 & 225.70 & 5030 & 3.39 & Foraminifer lithic sandstone \\
\hline 16 & 237.59 & 5041 & 3.56 & Lapillistone \\
\hline 17 & 257.54 & 5058 & 3.83 & Lapillistone (weak reflector, low continuity) \\
\hline 18 & 267.67 & 5070 & 4.24 & Silty, foraminifer nannofossil chalk (weak reflector) \\
\hline 19 & 278.07 & 5081 & 4.48 & Nannofossil chalk (weak, discontinuous reflector) \\
\hline 20 & 296.19 & 5099 & 4.91 & Density/velocity increase in a nannofossil chalk sequence \\
\hline 21 & 313.12 & 5118 & 5.32 & Lithic crystal sand \\
\hline 22 & 325.53 & 5130 & 5.61 & Indurated nannofossil ooze (weak reflector) \\
\hline 23 & 337.50 & 5144 & 5.90 & Clay with nannofossils (grading to lithic crystal sand), weak reflector \\
\hline 24 & 350.81 & 5157 & 6.21 & Slump unit consisting of ooze, clay, silt, mixed rock \\
\hline 25 & 361.35 & 5167 & 6.21 & ? \\
\hline 26 & 385.85 & 5185 & 7.60 & Foraminifer lithic crystal sand (weak, discontinuous reflector) \\
\hline 27 & 399.73 & 5200 & 8.28 & Indurated clay with nannofossil (weak and discontinuous reflector) \\
\hline 28 & 409.80 & 5210 & 8.46 & Calcareous sandstone? \\
\hline 29 & 417.79 & 5219 & 8.60 & Indurated clay? \\
\hline 30 & 442.71 & 5242 & 9.03 & Silty claystone \\
\hline 31 & 455.00 & 5254 & 9.25 & Claystone? \\
\hline 32 & 470.39 & 5271 & 9.52 & Nannofossil chalk? \\
\hline 33 & 495.30 & 5293 & 9.96 & Lithic crystal sandstone? \\
\hline 34 & 516.44 & 5312 & 10.33 & Nannofossil claystone \\
\hline 35 & 556.83 & 5350 & 11.04 & Lithic crystal sandstone \\
\hline 36 & 594.71 & 5385 & 11.71 & Lithic crystal sandstone \\
\hline 37 & 601.86 & 5390 & 11.82 & Lapillistone \\
\hline 38 & 621.49 & 5408 & 11.82 & Lithic crystal sandstone? \\
\hline 39 & 633.90 & 5419 & 11.98 & ? (logged but not recovered) \\
\hline 40 & 689.14 & 5467 & 12.71 & Siltstone \\
\hline 41 & 710.40 & 5485 & 12.99 & Siltstone? (weak and discontinuous reflector) \\
\hline 42 & 749.72 & 5519 & 13.37 & Nannofossil claystone, graded to crystal siltstone \\
\hline 43 & 755.34 & 5524 & 13.41 & Claystone? (close to not sampled sandstone) \\
\hline 44 & 768.32 & 5535 & 13.50 & Vitric tuff \\
\hline 45 & 787.20 & 5552 & 13.63 & Calcareous vitric siltstone? (weak reflector) \\
\hline 46 & 794.45 & 5559 & 13.68 & Lithic crystal vitric tuff \\
\hline 47 & 822.44 & 5584 & 13.90 & Vitric rich claystone with sandy vitric tuff \\
\hline 48 & 842.17 & 5602 & 14.25 & Nannofossil claystone grading to lithic crystal sandstone with pumice \\
\hline 49 & 863.22 & 5618 & 14.61 & Claystone grading down to lithic crystal sandstone (weak reflector) \\
\hline 50 & 920.42 & 5660 & $14.80-15.80$ & Lapillistone with basaltic breccia \\
\hline 51 & 988.44 & 5709 & $14.80-15.80$ & Pebble- and granule-sized, fine-grained hyaloclastite tuff \\
\hline 52 & 1029.97 & 5737 & $>15.80$ & High velocity unit in hyaloclastite lapillistone \\
\hline 53 & 1066.83 & 5756 & $>15.80$ & Transition from hyaloclastite lapillistone breccia to hyaloclastite tuff \\
\hline 54 & 1110.61 & 5781 & $>15.80$ & Transition from basaltic hyaloclastite breccia to hyaloclastite tuff \\
\hline 55 & 1139.86 & 5797 & $>15.80$ & Transition from hyaloclastite breccia to hyaloclastite lapillistone \\
\hline
\end{tabular}

Notes: ? = reflection not fully determined. Reflector numbers are shown in Figure 4. Unless specified, the reflections are caused by thin layers of the given lithology intercalated to background sediments with a different impedance.

wise low correlation between lithologic boundaries and their seismic expression.

The narrow spacing of the volcaniclastic deposits in conjunction with the drilling allows a high temporal resolution of the apron. The nonvolcanic background sediments represent an ideal contrast medium for seismic detection of thin volcaniclastic layers. Hence, a seismic investigation in a volcanic apron benefits from high background sedimentation rates like around the Canary Islands.

\section{ACKNOWLEDGMENTS}

We are grateful to the crew and scientific staff of the research vessels Meteor and JOIDES Resolution for collecting the data in a professional manner. Some figures were generated with software provided by P. Wessel and W.F.H. Smith (1991). The work on this paper was supported by the Deutsche Forschungsgemeinschaft (DFGSchm250/49 III GK, DFG-Schm250/54), the Bundesministerium für Forschung und Technologie, and the European Union $(\mathrm{EPOCH}$, EVSV-CT93-0283, MAS2-CT94-0083).

\section{REFERENCES}

Ancochea, E., Fúster, J.M., Ibarrola, E., Cendrero, A., Coello, J., Hernán, F., Cantagrel, J.M., and Jamond, C., 1990. Volcanic evolution of the island of Tenerife (Canary Islands) in the light of new K-Ar data. J. Volcanol. Geotherm. Res., 44:231-249.

Badley, M.E., 1985. Practical Seismic Interpretation: Englewood Cliffs, NJ (Prentice Hall).

Funck, T., 1996. Structure of the volcanic apron north of Gran Canaria deduced from reflection seismic, bathymetric and borehole data [Ph.D. dissert.]. Univ. Kiel.

Funck, T., Dickmann, T., Rihm, R., Krastel, S., Lykke-Andersen, H., and Schmincke, H.-U., 1996. Reflection seismic investigations in the volcaniclastic apron of Gran Canaria and implications for its volcanic evolution. Geophys. J. Int., 125: 519-536.

Hoernle, K., and Schmincke, H.-U., 1993a. The role of partial melting in the 15-Ma geochemical evolution of Gran Canaria: a blob model for the Canary Hotspot. J. Petrol., 34:599-627.

1993b. The petrology of the tholeiites through melilite nephelinites on Gran Canaria, Canary Islands: crystal fractionation, accumulation, and depths of melting. J. Petrol., 34:573-597.

Larsen, H.C., Saunders, A.D., Clift, P.D., et al., 1994. Proc. ODP, Init. Repts., 152: College Station, TX (Ocean Drilling Program). 
Schmincke, H.-U., 1976. The geology of the Canary Islands. In Kunkel, G. (Ed.), Biogeography and Ecology in the Canary Islands: The Hague (W. Junk), 67-184.

1982. Volcanic and chemical evolution of the Canary Islands. In von Rad, U., Hinz, K., Sarnthein, M., and Seibold, E. (Eds.), Geology of the Northwest African Continental Margin: Berlin (Springer), 273-306.

1994. Geological Field Guide: Gran Canaria (7th ed.): Kiel, Germany (Pluto Press).

Schmincke, H.-U., and Rihm, R., 1994. Ozeanvulkan 1993, Cruise No. 24, 15 April-9 May 1993. METEOR-Berichte, Univ. Hamburg, 94-2.

Schmincke, H.-U., Weaver, P.P.E., Firth, J.V., et al., 1995. Proc. ODP, Init. Repts., 157: College Station, TX (Ocean Drilling Program).

von Rad, U., Ryan, W.B.F., et al., 1979. Init. Repts. DSDP, 47 (Pt. 1): Washington (U.S. Govt. Printing Office).
Wessel, P., and Smith, W.H.F., 1991. Free software helps map and display data. Eos, 72:441, 445-446.

Wissmann, G., 1979. Cape Bojador slope, an example for potential pitfalls in seismic interpretation without the information of outer margin drilling. In von Rad, U., Ryan, W.B.F., et al., Init. Repts. DSDP, 47 (Pt. 1): Washington (U.S. Govt. Printing Office), 491-499.

Date of acceptance: 6 January 1997

Date of initial receipt: 24 June 1996

Ms 157SR-100 


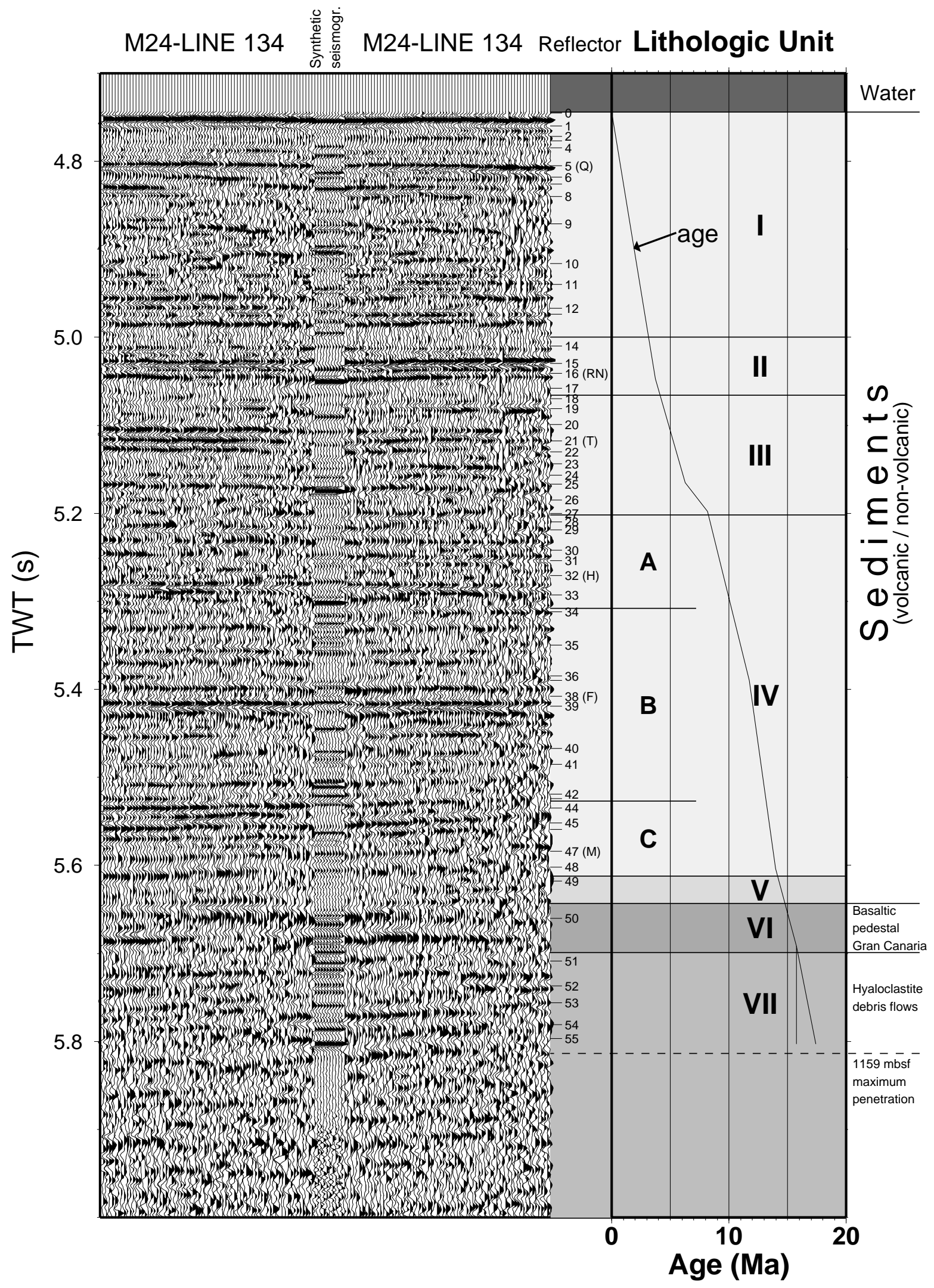

Figure 4. Part of seismic Line P134 with synthetic seismogram at Site 953 and the lithologic units converted to TWT (in seconds below sea level). The two age lines in lithologic Unit VII give minimum and maximum ages. The small numbers to the right of the seismic data refer to individual reflectors as listed in Table 1 . 